\title{
The intensity of extremely low frequency
} electromagnetic field by target temperature of MEGAWARMER ${ }^{\circledR}$ patient temperature management system

\author{
Se Hun Kim, MD $\bowtie$, Yei Heum Park, MD $\bowtie$, Hyunseong Lee, MD $\bowtie$, \\ Sang Eun Lee, MD, PhD $\bowtie$, Jae Hong Park, MD, PhD $\bowtie$, Ki Hwa Lee, MD, PhD $\square$, \\ Yong Han Kim, MD, PhD* \\ Author affiliations: \\ Department of Anesthesiology and Pain Medicine, Haeundae Paik Hospital of Inje University, 875, Haeun-daero, Haeundae-gu, \\ Busan, Republic of Korea \\ *Corresponding author: Yong Han Kim, MD; E-mail: adonis94@naver.com; Tel:+82-51-797-0478; Fax: +82-51-797-0499
}

\section{Abstract}

Background: Extremely low frequency electromagnetic field (ELF-EMF) emitted by electronic devices is associated with various biological effects on the human body. MEGAWARMER ${ }^{\circledR}$ patient temperature management system (PTMS) is widely used for the patient temperature management in anesthesia and critical care. We investigated the intensity of ELF-EMF according to the distance and target temperature of MEGAWARMER ${ }^{\circledR}$ PTMS to find the distance allowing minimized exposure to ELF-EMF.

Methodology: This study was a prospective experimental study. Target temperature was set at $31^{\circ} \mathrm{C}, 36^{\circ} \mathrm{C}$ and $41^{\circ} \mathrm{C}$. After setting each target temperature, the intensity of ELF-EMF was measured 300 times during 10 min at interval of $2 \mathrm{sec}$, at distances of 15, 30, and $45 \mathrm{~cm}$ from the MEGAWARMER ${ }^{\circledR}$ PTMS, respectively. Nine measurement groups from 3 different target temperatures and 3 different distances resulted in 2700 data. Including background EMF intensity with the MEGAWARMER ${ }^{\circledR}$ PTMS also turned off, total 3000 data in 10 groups were collected.

Results: At the distance of $15 \mathrm{~cm}$ from the MEGAWARMER ${ }^{\circledR}$ PTMS, mean values of ELF-EMF were 4.6721 milligauss (mG), where $1 \mathrm{G}$ is equivalent to $10^{-4}$ Tesla ( $\mathrm{T}$ ) (or $1 \mathrm{mG}=0.1 \mu \mathrm{T}$ ) at $31^{\circ} \mathrm{C}, 4.2852 \mathrm{mG}$ at $36^{\circ} \mathrm{C}$, and $3.9935 \mathrm{mG}$ at $41^{\circ} \mathrm{C}$. At the distance of $30 \mathrm{~cm}$, mean values of ELF-EMF were $2.0948 \mathrm{mG}$ at $31^{\circ} \mathrm{C}, 2.0790 \mathrm{mG}$ at $36^{\circ} \mathrm{C}$, and $2.0633 \mathrm{mG}$ at $41^{\circ} \mathrm{C}$. At the distances of $15 \mathrm{~cm}$ and $30 \mathrm{~cm}$, the lower target temperature showed statistically significantly higher mean values of ELF-EMF ( $p<0.05)$. In all three target temperatures, longer distance made statistically significantly lower mean value of ELF-EMF $(p<0.05)$.

Conclusions: The mean intensity of ELF-EMF from the MEGAWARMER ${ }^{\circledR}$ Patient Temperature Management at the distance of $15 \mathrm{~cm}$ and $30 \mathrm{~cm}$ exceeded $2 \mathrm{mG}$ recommended by Swedish Confederation of Professional Employees guideline.

Key words: Extremely low frequency electromagnetic field; Temperature management; Intensive care unit

Abbreviations: ELF-EMF- Extremely Low Frequency ElectroMagnetic Field; PRMS - Patient Temperature Management System; $m G$ - milligauss

Citation: Kim SH, Park YH, Lee H, Lee SE, Park JH, Lee KH, Kim YH. The intensity of extremely low frequency electromagnetic field by target temperature of MEGAWARMER $\mathbb{R}$ patient temperature management system.

741 www.apicareonline.com 
Anaesth. pain intensive care 2021;25(6):741-745; DOI: 10.35975/apic.v25i6.1693

Received: August 11, 2021, Reviewed: September 30, 2021, Accepted: October 6, 2021

\section{Introduction}

Using electronic devices increases environmental and occupational exposure to extremely low frequency electromagnetic field (ELF-EMF), ${ }^{1}$ which is defined by frequencies from 3 to $3000 \mathrm{~Hz}$ and produced by electrical currents that have wavelengths of 50 or 60 $\mathrm{Hz}^{2}$

Although the effects of ELF-EMF on human body are not fully explained, several studies have reported the relationship between ELF-EMF and a range of biological effects on human body. ${ }^{1}$ Focused on this link between ELF-EMF and the diseases, many studies have reported that ELF-EMF increases the risk of development of cancer, including leukemia, brain tumor, breast cancer, testicular cancer and cancer of the corpus uteri. ${ }^{3-6}$ The International Agency for Research on Cancer (IARC) classifies ELF-EMF as Group 2B, which means possibly carcinogenic to humans. ${ }^{7}$

Moreover, the association between occupational exposure to ELF-EMF and the risk of Alzheimer disease has been suggested, ${ }^{8,9}$ and an increased risk of amyotrophic lateral sclerosis has also been reported with the jobs having relatively high levels of ELF-EMF exposure. ${ }^{10}$ Chronic exposure to ELF-EMF by the power plant workers, effects their sleep quality, and exposes them to higher stress, depression and anxiety levels than the unexposed group. ${ }^{11,12}$ The guideline of the Swedish Confederation of Professional Employees (Tjänstemännens Centralorganisation, TCO) recommends the intensity of ELF-EMF should be under 2 milligauss $(\mathrm{mG})$, at a distance of $30 \mathrm{~cm}^{13}$

In hospitals, especially in operating rooms and intensive care units, there are numerous electronic medical devices. Medical staff working there may have relatively high risk of occupational exposure to ELF-EMF. Yet only few studies have been conducted to measure ELF$\mathrm{EMF}$ in the operating rooms, intensive care units, and for each electronic medical device.

MEGAWARMER $^{\circledR}$ patient temperature management system (PTMS) (MEGAWARMER ${ }^{\circledR}$, Medwin Co., Ltd., Korea) is widely used for the temperature management in anesthesia and critical care. Several technologies have been in use to manage patients temperature, including external water circulating blanket, gel-coated adhesive pad and endovascular balloon catheter. ${ }^{14}$ Among these technologies, MEGAWARMER ${ }^{\circledR}$ PTMS uses surface warming and surface cooling by using external water circulating blanket. After filling water storage of the device with water of room temperature, the device can warm or cool the water to the target temperature using magnetic pump operated by electricity. This water circulates through the connected blanket which patients can lie on or be covered, for providing surface warming or surface cooling (Figure 1). This method is used widely because of its benefits that this device can be easily applied to patients and is not invasive. ${ }^{15}$ However, exposure to ELF-EMF emitted by this device and its effect on human body have not been reported despite its wide-spread use. We investigated the intensity of ELFEMF according to the distance and the target temperature of MEGAWARMER ${ }^{\circledR}$ PTMS to find the distance allowing minimal exposure to ELF-EMF.

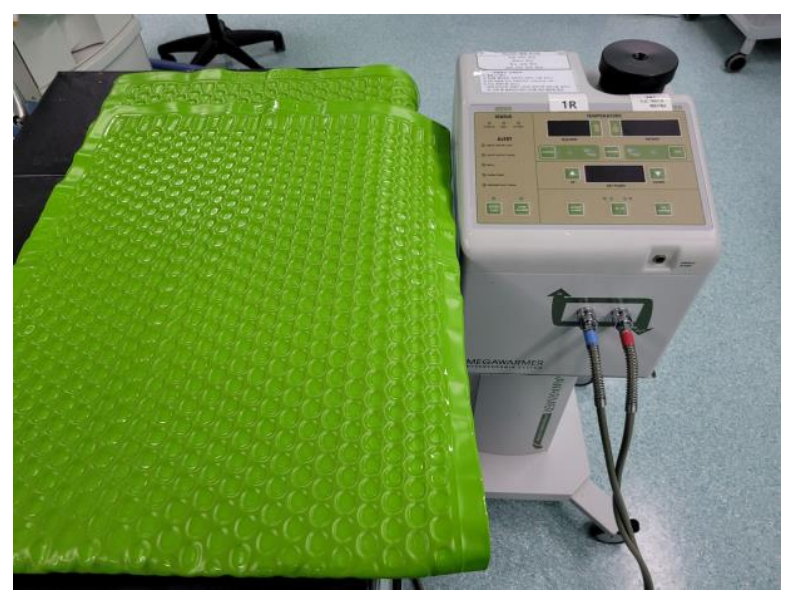

Figure 1: MEGAWARMER ${ }^{\circledR}$ PTMS with reusable patient blanket (Medwin Co., Ltd., Korea).

\section{Methodology}

This study was a prospective experimental study, conducted in an empty operating room. All electronic devices in this room were turned off during experiment except MEGAWARMER ${ }^{\circledR}$ PTMS. The experiment was conducted at night when other operating rooms were also empty. The intensity of ELF-EMF was measured by ELF-EMF meter (Triaxial Magnetic Field Meter, TM-192D, Tenmars Electronics Co., Taiwan) at the anterior surface of MEGAWARMER ${ }^{\circledR}$ PTMS that showed the highest intensity of ELF-EMF than another three surfaces showed. Target temperature was set at $31^{\circ} \mathrm{C}, 36^{\circ} \mathrm{C}$ and $41^{\circ} \mathrm{C}$. After setting $31^{\circ} \mathrm{C}$, the intensity 
of ELF-EMF was measured 300 times during 10 min at interval of $2 \mathrm{sec}$, at distance of $15 \mathrm{~cm}$ from the anterior surface of the device. Measurement at distances of $30 \mathrm{~cm}$ was followed, measuring 300 times during $10 \mathrm{~min}$ at interval of $2 \mathrm{sec}$. Then, measurements at a distance of $45 \mathrm{~cm}$ were done, measuring 300 times during $10 \mathrm{~min}$ at interval of 2 sec. At $36^{\circ} \mathrm{C}$ and $41^{\circ} \mathrm{C}$, same method was applied, respectively; resulting in 2700 data and 9 measurement groups from 3 different target temperatures and 3 different distances. Including background EMF intensity with the MEGAWARMER ${ }^{\circledR}$

PTMS also turned off, 3000 data in 10 groups were collected and analyzed.

Statistical analysis: Sample size was calculated using MedCalc 12.4.0 (Medcalc software, Ostend, Belgium). A sample size of 250 data in each group was computed to detect a difference with a type I error of 0.05 and a power of $80 \%$. Data were calculated for mean and standard deviation for each combination and compared using Kruskal-Wallis test. A p $<0.05$ was considered to be statistically significant.

\section{Results}

The intensity of ELF-EMF at three different distances and three different target temperatures is summarized in Table 1. Background EMF intensity with the MEGAWARMER ${ }^{\circledR}$ PTMS turned off was $1.8198 \pm 0.0108 \mathrm{mG}$.

At the distances of $15 \mathrm{~cm}$ and $30 \mathrm{~cm}$, the lower target temperature showed statistically significant higher mean values of ELF-EMF $(p<0.05)$. And the mean intensity of ELF-EMF at the distance of $15 \mathrm{~cm}$ and $30 \mathrm{~cm}$ exceeded $2 \mathrm{mG}$ recommended by TCO guideline. At the distance of $45 \mathrm{~cm}$, the lower target temperature showed also higher mean values of ELF-EMF, but it was not statistically significant $(\mathrm{p}=0.0882)$. At the distance of $45 \mathrm{~cm}$, the mean intensity of ELF-EMF did not exceed $2 \mathrm{mG}$ recommended by TCO guideline. In all three target temperatures, longer distance made significantly lower mean value of ELF-EMF ( $p<0.05)$.

\section{Discussion}

ELF-EMF is produced by numerous electronic devices; therefore, the people can be exposed to various intensities of ELF-EMF. ${ }^{1-2}$ Many epidemiologic and biologic studies have reported various effects and the hazards of ELF-EMF on human body. ${ }^{3-6,8-12,16-17}$

\section{Table 1: The intensity of extremely low frequency electromagnetic field (ELF-EMF) on various levels of target temperature and distance}

\begin{tabular}{|c|c|c|}
\hline $\begin{array}{l}\text { Distance } \\
(\mathrm{cm})\end{array}$ & $\begin{array}{l}\text { Target } \\
\text { Temperature }\left({ }^{\circ} \mathrm{C}\right)\end{array}$ & $\begin{array}{l}\text { Electromagnetic Field } \\
\text { Intensity (mG) }\end{array}$ \\
\hline \multirow[t]{3}{*}{15} & 31 & $4.6721 \pm 0.3370$ * $\dagger$ \\
\hline & 36 & $4.2852 \pm 0.3433$ * \\
\hline & 41 & $3.9935 \pm 0.3274$ †† \\
\hline \multirow[t]{3}{*}{30} & 31 & $2.0948 \pm 0.0258$ §ণ \\
\hline & 36 & $2.0790 \pm 0.0358 \S П$ \\
\hline & 41 & $2.0633 \pm 0.0423$ ПП \\
\hline \multirow[t]{3}{*}{45} & 31 & $1.8681 \pm 0.0128$ \\
\hline & 36 & $1.8679 \pm 0.0132$ \\
\hline & 41 & $1.8661 \pm 0.0148$ \\
\hline
\end{tabular}

Data presented as Mean $\pm S D$, in $m G$.

* represents statistically significant difference between group $31^{\circ} \mathrm{C}$ and $36^{\circ} \mathrm{C}$ at distance of $15 \mathrm{~cm}(p<0.05)$

t represents statistically significant difference between group $31^{\circ} \mathrm{C}$ and $41^{\circ} \mathrm{C}$ at distance of $15 \mathrm{~cm}(p<0.05)$

$\ddagger$ represents statistically significant difference between group $36^{\circ} \mathrm{C}$ and $41^{\circ} \mathrm{C}$ at distance of $15 \mathrm{~cm}(p<0.05)$

$\S$ represents statistically significant difference between group $31^{\circ} \mathrm{C}$ and $36^{\circ} \mathrm{C}$ at distance of $30 \mathrm{~cm}(p<0.05)$

I represents statistically significant difference between group $31^{\circ} \mathrm{C}$ and $41^{\circ} \mathrm{C}$ at distance of $30 \mathrm{~cm}(p<0.05)$

$\Pi$ represents statistically significant difference between group

$36^{\circ} \mathrm{C}$ and $41^{\circ} \mathrm{C}$ at distance of $30 \mathrm{~cm}(p<0.05)$
In hospital, especially in operating rooms and intensive care units, there are numerous electronic medical devices in a small space, so risk of occupational exposure of medical staffs to ELF-EMF may be inevitable. In 19 empty operating rooms, the intensity of ELF-EMF was measured to be $2.22 \pm 1.13 \mathrm{mG}$ at a distance of $30 \mathrm{~cm}$ from the monitoring screen, where the anesthesiologists usually stand. ${ }^{18}$ In day time when surgical operations are usually performed, the intensity of ELF-EMF more than $2 \mathrm{mG}$ was measured at the usual standing position of the anesthesiologists during $70 \%$ of the working time. ${ }^{19}$ In the studies using convective air warming system for hypothermia management and light source device for vision during surgery, the intensity of ELF-EMF at a distance of $30 \mathrm{~cm}$ from each device was more than $2 \mathrm{mG}^{20-21}$ In one adult intensive care unit, about $83 \%$ of patients were exposed to ELF-EMF above $2 \mathrm{mG}$ emitted by surrounding electronic medical 
devices. $^{22}$

In the present study, we investigated the intensity of ELF-EMF according to the distance and target temperature of MEGAWARMER ${ }^{\circledR}$ PTMS. Temperature management is very important and crucial in anesthesia and critical care, ${ }^{15,23}$ and MEGAWARMER ${ }^{\circledR}$ PTMS has been successfully employed to play a role in this area.

In this study, at a distance of $15 \mathrm{~cm}$ and $30 \mathrm{~cm}$, the mean intensity of ELF-EMF of all target temperatures exceeded $2 \mathrm{mG}$ recommended by TCO guideline, unlike at a distance of $45 \mathrm{~cm}$, where the mean intensity of ELFEMF of all target temperature did not exceed $2 \mathrm{mG}$. Therefore, using MEGAWARMER ${ }^{\circledR}$ PTMS at a distance of $30 \mathrm{~cm}$ can expose medical staff to ELF-EMF more than $2 \mathrm{mG}$.

From the results of this study, we cannot conclude that exposure to ELF-EMF from the MEGAWARMER ${ }^{\circledR}$ PTMS at a distance of $30 \mathrm{~cm}$ makes adverse effect on medical staffs. Further studies related to exposure to ELF-EMF and degree of adverse effects are needed. However, this study indicates the safe distance allowing minimized exposure to ELF-EMF.

\section{Conclusion}

The mean intensity of ELF-EMF from the MEGAWARMER ${ }^{\circledR}$ Patient Temperature Management at a distance of $15 \mathrm{~cm}$ and $30 \mathrm{~cm}$ exceeds $2 \mathrm{mG}$ recommended by Swedish Confederation of Professional Employees guideline. At a distance of 45 $\mathrm{cm}$, the mean intensity of ELF-EMF does not exceed 2 $\mathrm{mG}$. Based on this result, medical staff in operating rooms and intensive care units can use the MEGAWARMER ${ }^{\circledR}$ Patient Temperature Management System in a distance allowing minimized exposure to ELF-EMF.

\section{Acknowledgements}

This work was supported by a 2019 Inje University research grant.

\section{Conflicts of Interests}

None declared by the authors

\section{Author's' contribution}

KHL, YHK: Concept and design of study

YHP, HL, SEL: Analysis and interpretation of data

SHK, JHP, YHK: Drafting and revising the paper, final review

\section{References}

1. D'Angelo C, Costantini E, Kamal MA, Reale M. Experimental model for ELF-EMF exposure: Concern for human health. Saudi J Biol Sci. 2015;22(1):75-84. [PubMed] DOI: 10.1016/j.sjbs.2014.07.006

2. Gajšek $P$, Ravazzani $P$, Grellier J, Samaras $T$, Bakos J, Thuroczy $G$. Review of studies concerning electromagnetic field (EMF) exposure assessment in Europe: Low frequency fields $(50 \mathrm{~Hz}-100 \mathrm{kHz})$. Int $\mathrm{J}$ Environ Res Public Health. 2016;13(9):875. [PubMed] DOI: 10.3390/ijerph13090875

3. Wertheimer $\mathrm{N}$, Leeper E. Electrical wiring configurations and childhood cancer. Am J Epidemiol. 1979;109(3):273-84. [PubMed] DOI: 10.1093/oxfordjournals.aje.a112681

4. Baldi I, Coureau G, Jaffre A, Gruber A, Ducamp S, Provost D, et al. Occupational and residential exposure to electromagnetic fields and risk of brain tumors in adults: a case-control study in Gironde, France. Int J Cancer. 2011;129(6):1477-84. [PubMed] DOI: 10.1002/ijc.25765

5. Chen Q, Lang L, Wu W, Xu G, Zhang X, Li T, et al. A metaanalysis on the relationship between exposure to ELF-EMFs and the risk of female breast cancer. PLoS One. 2013;8(7):e69272. [PubMed] DOI: 10.1371/journal.pone.0069272

6. Floderus B, Stenlund C, Persson T. Occupational magnetic field exposure and site-specific cancer incidence: a Swedish cohort study. Cancer Causes Control. 1999;10(5):323-32. [PubMed] DOI: 10.1023/a:1008953920877

7. International Agency for Research on Cancer Working Group on the Evaluation of Carcinogenic Risks to Humans. Nonionizing radiation, Part 1: Static and extremely low frequency electric and magnetic fields. IARC Monogr Eval Carcinog Risks Hum. 2002;80:1-395. [PubMed]

8. Garcia AM, Sisternas A, Hoyos SP. Occupational exposure to extremely low frequency electric and magnetic fields and Alzheimer disease: a meta-analysis. Int $\mathrm{J}$ Epidemiol. 2008;37(2):329-40. [PubMed] DOI: 10.1093/ije/dym295

9. Roosli M. Commentary: Epidemiological research on extremely low frequency magnetic fields and Alzheimer's disease--biased or informative? Int $J$ Epidemiol. 2008;37(2):341-3. [PubMed] DOI: 10.1093/ije/dyn024

10. Zhou H, Chen G, Chen C, Yu Y, Xu Z. Association between extremely low-frequency electromagnetic fields occupations and amyotrophic lateral sclerosis: a meta-analysis. PLoS One. 2012;7(11):e48354. [PubMed] DOI: 10.1371/journal.pone.0048354

11. Bagheri Hosseinabadi M, Khanjani N, Ebrahimi MH, Haji B, Abdolahfard $\mathrm{M}$. The effect of chronic exposure to extremely low-frequency electromagnetic fields on sleep quality, stress, depression and anxiety. Electromagn Biol Med. 2019;38(1):96101. [PubMed] DOI: $10.1080 / 15368378.2018 .1545665$

12. Yousefi HA, Nasiri P. Psychological effects of occupational exposure to electromagnetic fields. J Res Health Sci.

744 www.apicareonline.com 
2006;6(1):18-21. [FreeFullText]

13. Rudling J NH. TCO'06 Media Displays: Version 1.2. Sweden: TCO Development; 2006.

14. Sonder $P$, Janssens $G N$, Beishuizen $A$, Henry $C L$ Rittenberger JC, Callaway CW, et al. Efficacy of different cooling technologies for therapeutic temperature management: A prospective intervention study. Resuscitation. 2018:124:14-20. [PubMed] DOI: 10.1016/j.resuscitation.2017.12.026

15. Jeon SB. Therapeutic hypothermia in the intensive care unit. J Neurocrit Care. 2014;7(1):6-15. DOI: 10.18700/jnc.2014.7.1.6

16. Wei J, Sun J, Xu H, Shi L, Sun L, Zhang J. Effects of extremely low frequency electromagnetic fields on intracellular calcium transients in cardiomyocytes. Electromagn Biol Med. 2015;34(1):77-84. 10.3109/15368378.2014.881744

17. Kim SJ, Jang YW, Hyung KE, Lee DK, Hyun KH, Jeong SH, et al. Extremely low-frequency electromagnetic field exposure enhances inflammatory response and inhibits effect of antioxidant in RAW 264.7 cells. Bioelectromagnetics. 2017;38(5):374-85 [PubMed] DOI: 10.1002/bem.22049

18. Lee JH, Lee HC, Kim HD, Kim JY, Kim DW, Nam YT, et al.
How much are anesthesiologists exposed to electromagnetic fields in operating rooms? Yonsei Med J. 2003;44(1):133-7. [PubMed] DOI: 10.3349/ymj.2003.44.1.133

19. Roh JH, Kim DW, Lee SJ, Kim JY, Na SW, Choi SH, et al. Intensity of extremely low-frequency electromagnetic fields produced in operating rooms during surgery at the standing position of anesthesiologists. Anesthesiology. 2009;111(2):275-8. [PubMed] DOl: 10.1097/ALN.0b013e3181a9188b

20. Cho KR, Kim MH, Ko MJ, Jung JW, Lee KH, Park YH, et al. Extremely low frequency electromagnetic field from convective air warming system on temperature selection and distance. Iran J Public Health. 2014;43(12):1635-9. [PubMed]

21. Jo HJ, Kim JH, Park YH, Lee H, Kim YH. The Intensity of Extremely Low Frequency Electromagnetic Field by Distance and Brightness of Luxtec $₫$ at the rate Light Source device. Rawal Med J. 2019;44(4):744-7. [FreeFullText]

22. Petrucci N. Exposure of the critically ill patient to extremely lowfrequency electromagnetic fields in the intensive care environment. Intensive Care Med. 1999;25:847-851. [PubMed] DOI: 10.1007/s001340050963

23. Kim D. Postoperative hypothermia. Acute Crit Care. 2019;34(1):79-80. [PubMed] DOI: 10.4266/acc.2018.00395 